\title{
Spatial distribution and importance of potential perfluoroalkyl acid precursors in urban rivers and sewage treatment plant effluent - Case study of Tama River, Japan
}

\section{Feng Ye ${ }^{1 *}$, Masahiro Tokumura ${ }^{1}$, Md Saiful Islam ${ }^{1}$, Yasuyuki Zushi ${ }^{2}$, Jungkeun $\mathrm{Oh}^{1}$, Shigeki Masunaga ${ }^{1}$}

${ }^{1}$ Faculty and Graduate School of Environment and Information Sciences, Yokohama National University, Yokohama, Japan

${ }^{2}$ National Institute for Environmental Studies, 16-2 Onogawa, Tsukuba 305-8506, Japan

*Corresponding author: Tel: +81-4-5339-4352; Fax: +81-4-5339-4373; E-mail: ye-feng-fy@ynu.jp

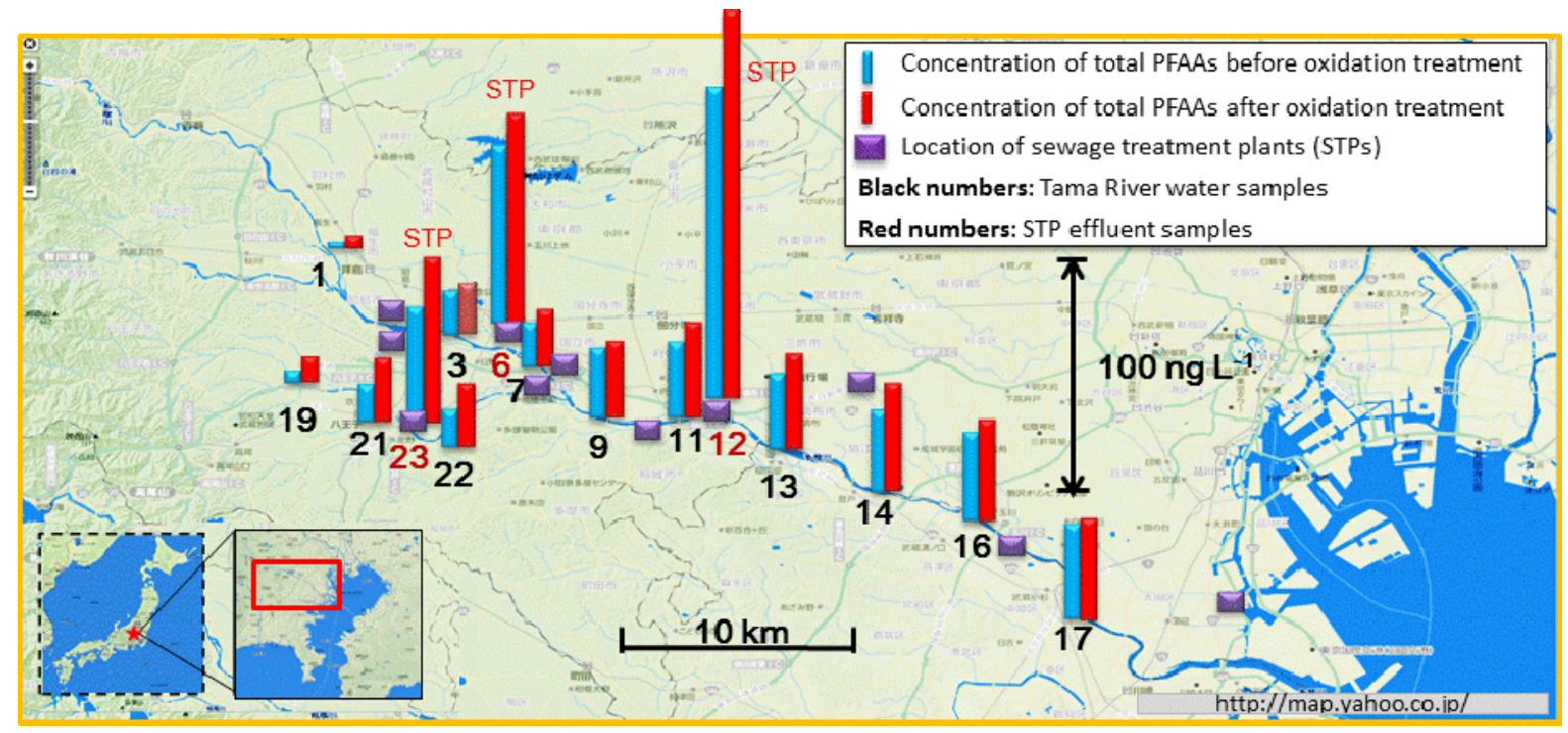

\section{Highlights}

- Significant amount of PFCAs was formed by the oxidation treatment of river water.

- Upstream river water had a higher potential PFAA precursor/LPFAA than STP effluent.

- STPs effluents were important sources of precursors to river. 


\begin{abstract}
Production and use of perfluorooctane sulfonate (PFOS) is regulated worldwide. However, numerous potential precursors that eventually decompose into PFOS and other perfluoroalkyl acids (PFAAs) such as perfluorooctanoic acid (PFOA) are still being used and have not been studied in detail. Therefore, knowledge about the levels and sources of the precursors is essential. We investigated the total concentration of potential PFAA precursors in the Tama River, which is one of the major rivers flowing into the Tokyo Bay, by converting all the perfluorinated carboxylic acid (PFCA) and perfluoroalkyl sulfonic acid (PFSA) precursors into PFCAs by chemical oxidation. The importance of controlling PFAA precursors was determined by calculating the ratios of PFCAs formed by oxidation to the PFAAs originally present $\left(\Sigma \Delta\right.$ PFCA $\left.\left._{\mathrm{C} 4-\mathrm{C} 12}\right] / \Sigma[\mathrm{PFAAs}]_{\text {before oxidation }}\right)$ (average $=0.28$ and 0.69 for main and tributary branch rivers, respectively). Higher total concentrations of $\Delta$ [PFCAs] were found in sewage treatment plant (STP) effluents. However, the ratios found in the effluents were lower (average $=0.21$ ) than those found in the river water samples, which implies the decomposition of some precursors into PFAAs during the treatment process. On the other hand, higher ratios were observed in the upstream water samples and the existence of emission sources other than the STP effluents was indicated. This study showed that although the treatment process converting a part of the PFAA precursors into PFAAs, STPs were important sources of precursors to the Tama River. To reduce the levels of PFAAs in the aquatic environment, it is necessary to reduce the emission of the PFAA precursors as well.
\end{abstract}

Keywords: effluent; oxidation; perfluorinated; perfluoroalkyl acid precursor; sewage treatment plant; Tama River 


\section{Introduction}

Perfluorooctane sulfonate (PFOS), the production of which was voluntarily phased out by its primary manufacturer in 2001/2002, was added to the list of persistent organic pollutants in the Stockholm Convention in 2009. Eight major manufacturers agreed to a PFOA stewardship program in conjunction with the US EPA to regulate PFCAs that are greater than $\mathrm{C} 7$, and that of their precursors. On the other hand, their production by other manufacturers might continue.. According to Butt et al. (2007), Hart et al. (2009), and Olsen et al. (2012), the PFOS concentration in tissues has decreased rapidly in human and wildlife species over the past decade; however, samples from some parts of the world have shown an increase in the levels of PFOS even after the 2002 phase-out (Long et al. (2012) and Reiner et al. (2011)). Moreover, Zushi et al. (2011) conducted a study on several major rivers in Tokyo and showed that significant changes in the PFOS and perfluorodecanoate (PFDA) concentration were not observed between 2005 and 2009 in some of the rivers, which suggests that the regulations on the use/production/emission of perfluoroalkyl acids (PFAAs) have not mitigated contamination of PFAAs in river water. In addition, a study by Gewurtz et al. (2013) on multimedia assessment including air, water, sediment, fish, and birds across Canada showed that the recent temporal trends varied depending on media and locations, and phase-outs and regulations were not consistently reflected in the temporal trends.

Some studies have focused on the PFAA precursors that eventually decompose into PFAAs such as PFOS and PFOA. In addition to being emitted during synthesis and use, PFAAs are produced from abiotic or biotic degradation of their precursors. Rhoads et al. (2008) and $\mathrm{Xu}$ et al. (2004) reported that the biotransformation of PFAA precursors is the potential source of PFAAs, e.g., the decomposition of perfluorooctane sulfonamide (FOSA) into PFOS. Butt et al. reviewed fluorotelomer-based polyfluoroalkyl substances, which ultimately degrade into PFCAs; numerous studies have shown that the metabolism of 8:2 FTOH results in the formation of PFOA (Butt et al., 2014). According to Murakami et al. (2009), Shivakoti et al. (2010), and Sun et al. (2012), the increase in the PFOA and other PFAA concentrations during the sewage treatment process is due to the biodegradation of their precursors. However, according to Benskin et al. (2012), Motegi et al. (2013), and Zushi et al. (2011), the total concentrations of a limited number of routinely monitored PFAA precursors in the river water were much lower than the concentration of the PFAAs. Martin et al. (2010) showed that only a small number of the numerous precursors available have been monitored, and hence, only limited information on these is available.

Buck et al. (2011) defined all the polyfluorinated alkyl substances by classifying them into various families and recommended a pragmatic set of common names and acronyms for the families as well as their individual members. Trier et al. (2011) identified more than 115 molecular structures of polyfluorinated surfactants in industrial blends (used to coat food paper and board packaging, and in packaging) from the European Union, the Unites States of America, and China. The occurrence of some precursors, namely polyfluoroalkyl phosphoric 
acid diesters in house dust and biosolid-applied soil were studied by De Silva et al. (2012) and Lee et al. (2014), respectively. Ahrens et al. (2011) reported that fluorotelomer alcohols, FOSAs, and perfluorooctane sulfonamidoethanols, which may be degraded to PFCAs or PFSAs in the atmosphere or under aerobic conditions, were emitted to the atmosphere from STPs and landfills. Since there are no routine analytical methods for most precursors, limited information regarding the occurrence of many individual precursors and the overall behaviors of the precursors is available.

Recently, Houtz and Sedlak (2012) developed a new method for quantifying the total concentration of PFAA precursors in urban runoff. In brief, water samples were exposed to hydroxyl radicals $\left({ }^{\circ} \mathrm{OH}\right)$ generated by the thermolysis of persulfate $\left(\mathrm{S}_{2} \mathrm{O}_{8}{ }^{2-}\right)$ under basic $\mathrm{pH}$ conditions. The PFAA precursors were transformed to PFCAs with the corresponding perfluorinated chain length. The concentrations of the total PFAA precursors could be inferred by comparing the PFCA concentrations before and after oxidation. It was reported that the total concentrations of PFCAs with 5-12 carbon chains increased owing to oxidation in the range from 2.8 to $56 \mathrm{ng} \mathrm{L}^{-1}$ (a $69 \%$ increase in the median compared to the concentration before oxidation) in runoff samples. The precursors that produced perfluorohexanoic acid (PFHxA) and perfluoropentanoic acid (PFPeA) upon oxidation were more prevalent than those that produced PFOA.

Limited information is available on the PFAA precursors which decompose into perand polyfluorinated alkyl substances. Thus, in this study, we studied the total PFAA precursor concentrations in the Tama River, which is one of the major rivers in Tokyo. According to the Bureau of Sewerage, Tokyo Metropolitan Government (2012), up to 50\% of the river water was composed of STP effluents. Hence, we applied the proposed method to demonstrate the increase of PFCAs by the oxidation of PFAA precursors ( $\triangle$ [PFCAs]). This method converts both PFCA and PFSA precursors into PFCAs, which is a potential source of PFAAs in river water. We showed the spatial distribution of PFAAs, including the $\triangle$ [PFCAs] from the PFAA precursors in urban river water and STP effluents. The importance of these PFAA precursors as a potential source of PFAA was determined by estimating the ratio of the PFCAs formed against PFAAs originally present $\left(\Sigma \Delta\left[\mathrm{PFCA}_{\mathrm{C} 4-\mathrm{C} 12]} / \Sigma[\mathrm{PFAAs}]_{\text {before oxidation }}\right)\right.$, and the importance of controlling the PFAA precursors was examined. To our knowledge, this is the first study to quantify the concentration of total PFAA precursors in urban river water and STP effluent samples and show the spatial distribution in a river system.

\section{Materials and Methods}

\subsection{Sample collection}

Sampling was conducted in the Tama River basin (Figure 1), and according to the Bureau of Sewerage, Tokyo Metropolitan Government (2012), the middle and downstream water reportedly consisted of approximately 50\% STP effluents. Twelve river water samples and 3 STP effluent samples were collected from upstream to downstream sites of the main river and 
its upstream tributaries on $7^{\text {th }}$ Oct. 2013 (Table S1). There was no rain on and before the day of sampling. Therefore, the influence of rainfall on the water flow was found to be minimal. Most of the river water samples were collected from the center of the river. The STP effluent samples were collected from the outflow of the plant connected to the river. The collected samples were decanted into methanol-rinsed $3 \mathrm{~L}$ high density polyethylene (HDPE) bottles and were kept in ice for up to $12 \mathrm{~h}$. Upon arrival at the laboratory, the samples were stored at $4{ }^{\circ} \mathrm{C}$ until analysis. Care was taken to avoid the usage of any PTFE-coated materials.

\subsection{PFAA precursor oxidation}

Hydroxyl radicals were produced by thermolysis of $\mathrm{S}_{2} \mathrm{O}_{8}{ }^{2-}$ under basic $\mathrm{pH}$ conditions. Tsao and Wilmarth (1959) showed that at $\mathrm{pH}$ values above 12 , thermolysis rapidly converts the $\mathrm{S}_{2} \mathrm{O}_{8}{ }^{2-}$ ion into the sulfate radical $\left(\mathrm{SO}_{4}{ }^{-\bullet}\right)$, which is then quickly converted to ${ }^{\circ} \mathrm{OH}$. The PFAA precursors are converted to PFCAs with the corresponding perfluorinated chain length. Gauthier and Mabury (2005) and Plumlee et al. (2009) showed that the PFOA was not oxidized appreciably by the ${ }^{\circ} \mathrm{OH}$. Based on the aforementioned observations, an oxidation method was developed by Houtz and Sedlak (2012) as follows: an excess of ${ }^{\circ} \mathrm{OH}$ was generated in the samples for the complete conversion of the PFAA precursors to PFCAs. In brief, $125 \mathrm{~mL}$ unfiltered water samples were transferred to $125 \mathrm{~mL}$ HDPE bottles. One sample from each site was subsampled in triplicate $(\mathrm{n}=3)$ and was added with $2 \mathrm{~g}(60 \mathrm{mM})$ of potassium persulfate and $1.9 \mathrm{~mL}$ of $10 \mathrm{~N} \mathrm{NaOH}(150 \mathrm{mM})$. The HDPE bottles were placed in a temperature-controlled oil bath (Personal H-10 SH; TAITEC, Saitama, Japan) at $85{ }^{\circ} \mathrm{C}$ for $6 \mathrm{~h}$. Then, the samples were cooled to room temperature in an ice bath prior to analysis. The $\mathrm{pH}$ of the samples was adjusted between 5 and 9 by concentrated $\mathrm{HCl}$ prior to the extraction.

\subsection{Extraction and analysis}

Isotope-labeled surrogate standards (Table S2) $4 \mathrm{ng}$ were added to the samples and blanks prior to the extraction in order to correct their recovery rates for each batch analysis. The original samples (before oxidation) and the samples obtained after the oxidation treatment were subjected to solid phase extraction (SPE) (Oasis WAX SPE cartridges, $6 \mathrm{~cm}^{3}, 150 \mathrm{mg}$, $30 \mu \mathrm{m}$; Waters, Milford, MA) which was a modified procedure of that reported by Taniyasu et al. (2005). The cartridges were preconditioned with $4 \mathrm{~mL}$ of $0.1 \% \mathrm{NH}_{4} \mathrm{OH}$ (in $\mathrm{CH}_{3} \mathrm{OH}$ ), $\mathrm{CH}_{3} \mathrm{OH}$, and ultra-pure water, respectively. Both the original and oxidized samples $(125 \mathrm{~mL})$ were pulled through the SPE cartridges under vacuum using a gum tube connected to a SPE manifold (GL Sciences, Tokyo, Japan). After sample loading, the HDPE bottles were rinsed with $4 \mathrm{~mL}$ of $50 \% \mathrm{CH}_{3} \mathrm{OH}$ in ultra-pure water, which was also pulled through the SPE cartridges for extraction. After extraction, the cartridges were rinsed with $4 \mathrm{~mL}$ of ultra-pure water and dried. Following the drying step, the SPE cartridges were eluted with $2 \mathrm{~mL}$ of $\mathrm{CH}_{3} \mathrm{OH}$ followed by $2 \mathrm{~mL}$ of $0.1 \% \mathrm{NH}_{4} \mathrm{OH}$ in $\mathrm{CH}_{3} \mathrm{OH}$. The eluate was evaporated to $400 \mu \mathrm{L}$ to avoid the loss of the target compounds during the drying process. The concentrations of the 14 PFAAs and 3 precursors of PFOS and PFOA (Table S2) were quantified by high performance liquid chromatography (HPLC, Agilent 1100LC, Agilent Technologies, Palo 
Alto, CA, USA) interfaced with a tandem mass spectrometer (MS/MS; Micromass Quattro, Waters, Milford, MA, USA).

\subsection{Method validation}

The total concentration of PFCAs was $0.42 \mathrm{ng} \mathrm{L}^{-1}$ in the blank tests without oxidation, whereas the concentration was $3.85 \mathrm{ng} \mathrm{L}^{-1}$ in the first blank oxidation test (blank conducted with ultra-pure water). By comparing the two tests, it was revealed that the total concentration of PFCAs in the first blank oxidation was about 9 times higher than that in the blank test without oxidation. The contamination in the first blank oxidation test may come from the precursors present in ultra-pure water (used instead of a real sample) and/or oxidation reagents. In the second blank test, oxidized ultra-pure water was used (contained no precursors). Therefore, the different concentration between the first and second blank tests was due to contamination from oxidation reagents and/or the operation of the experiment. As ultra-pure water was not used during the sample analysis, the increased concentration (in the second blank oxidation test as compared to that of the first test) was used as the oxidation blank to correct the measured values for each batch analysis. The total increase in

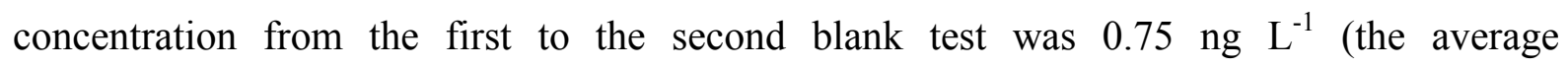
concentrations of PFAAs produced by oxidation in the upstream, downstream, and STP samples were $6.5,7.6$, and $16 \mathrm{ng} \mathrm{L}^{-1}$, respectively).Spike and recovery tests were performed. The recoveries of the target compounds, except for 8:2 FTCA and NMeFOSA, ranged from $53 \%$ to $126 \%$. Due to the low recovery of NMeFOSA $(4 \%)$, this compound was not quantified. Although the recovery of $8: 2$ FTCA (41\%) was less than $50 \%$, we quantified it as a reference value.

In our study, most of the samples were analyzed in triplicate and the median values were used for further studies because outliers were sometimes observed among the triplicate values.

\subsection{Statistical methods}

Statistical significance was computed using the $t$ test. Welch's $t$ test was used to determine the

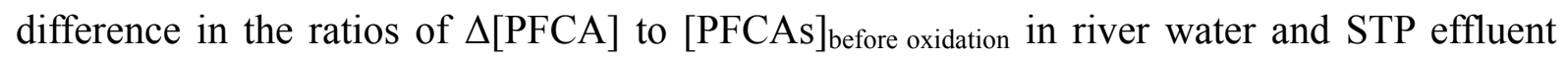
samples. Paired samples $t$ test was used to test the difference in the total concentrations of the paired samples before and after oxidation, and to determine the ratios of $\Delta[\mathrm{PFCA}]$ to

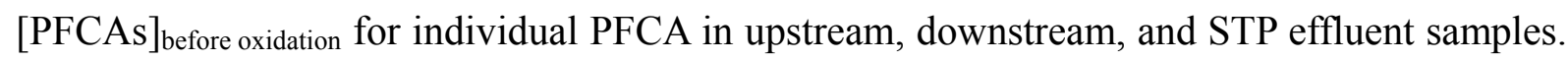
The difference was deemed to be significant when the $p$ was $<0.05$.

\section{Results and Discussion}

\subsection{Concentration of PFAAs and their precursors before oxidation}

The concentration of the 15 PFAA and 3 PFAA precursors before oxidation in the river water samples were 3.8-38 ng L ${ }^{-1}$ (average $=23 \mathrm{ng} \mathrm{L}^{-1}$ ) (Table S3). The most prevalent PFAAs in the river water samples were PFOS $\left(0.54-8.0 \mathrm{ng} \mathrm{L}^{-1}\right.$, average $\left.=5.1 \mathrm{ng} \mathrm{L}^{-1}\right)$, PFOA $(0.59-5.7$ ng $\mathrm{L}^{-1}$, average $\left.=3.7 \mathrm{ng} \mathrm{L}^{-1}\right)$, PFHxA $\left(0.25-5.0 \mathrm{ng} \mathrm{L}^{-1}\right.$, average $\left.=3.0 \mathrm{ng} \mathrm{L}^{-1}\right)$, and 
perfluorononanoate (PFNA) $\left(0.26-5.0 \mathrm{ng} \mathrm{L}^{-1}\right.$, average $\left.=2.8 \mathrm{ng} \mathrm{L}^{-1}\right)$. A study conducted by Zushi et al. (2011) reported that in 2009 two sites (a site close to site 17 and a site same as site 13 of this study) exhibited a PFOS concentration of 20 and $18 \mathrm{ng} \mathrm{L^{-1 }}$, PFOA concentration of 12 and $9 \mathrm{ng} \mathrm{L}^{-1}$, and PFNA concentration of 64 and $58 \mathrm{ng} \mathrm{L}{ }^{-1}$. These previously reported concentrations were higher by more than two times for PFOS and PFOA, and around 10 times for PFNA than those in sites 17 and 13 of this study. Murakami et al. (2008) reported that the high PFNA concentrations were due to the industrial production of PFCAs in Japan.

In the spatial distribution of the Tama River, an increase in the total concentration of the PFAAs and its precursors before oxidation was observed from sampling sites 1 to 17 of the main river and 19 to 22 of its branch (Figure 2a). Sites $1\left(3.8 \mathrm{ng} \mathrm{L}^{-1}\right)$ and $19\left(4.4 \mathrm{ng} \mathrm{L}^{-1}\right)$ were located at the upstream of the main river and one main branch, respectively and they exhibited the lowest total concentrations in each stream. In the study by Zushi et al. (2011), a similar concentration level $\left(2.7 \mathrm{ng} \mathrm{L}^{-1}\right)$ was observed at the site that was approximately $8 \mathrm{~km}$ upstream of site 1 in this study. According to Zushi and Masunaga (2011), the increase in the total concentration of the PFAAs was observed at sites where the population density was higher than that in the upper stream. This was explained by the high correlation between the dissolved perfluoroalkyl compound concentrations and population density.

The total concentrations of the 15 PFAAs and 3 PFAA precursors before oxidation in the STP effluent samples (sites 23, 6 and 12) were 48-109 $\mathrm{ng} \mathrm{L}^{-1}$ (average $=76 \mathrm{ng} \mathrm{L}^{-1}$ ) (Figure 2a). The most prevalent PFAAs were PFOS (11-31 ng L $\mathrm{L}^{-1}$, average $=19 \mathrm{ng} \mathrm{L}^{-1}$ ), PFHxS (5.6-24 ng L ${ }^{-1}$, average $\left.=13 \mathrm{ng} \mathrm{L}^{-1}\right)$, PFHxA $\left(5.8-17 \mathrm{ng} \mathrm{L}^{-1}\right.$, average $\left.=11 \mathrm{ng} \mathrm{L}^{-1}\right)$, and PFOA (9.0-12 $\mathrm{ng} \mathrm{L}^{-1}$, average $\left.=10 \mathrm{ng} \mathrm{L}^{-1}\right)$. The comparison of median concentrations showed that the concentrations of the PFAAs in the effluent samples were 2 to 5 times higher than those in the river water samples. Among all the samples, site 12 showed the highest total concentration (109 $\mathrm{ng} \mathrm{L}^{-1}$ ) for both the river water and STP effluent samples. Zushi et al. (2011) showed that the effluents of STPs which were located in different rivers in Tokyo had higher total concentrations than the river water. The aforementioned results indicated that the STP effluents constituted a non-negligible source of PFAAs in the aquatic environment.

The total concentrations of the C8 PFAA precursors, namely 8:2 fluorotelomer carboxylic acid, $N$-methyl perfluorooctane sulfonamide (NMeFOSA), FOSA, and di-perfluorooctane sulfonamidoethanol-based phosphate measured prior to oxidation were 0.04-0.61 ng $\mathrm{L}^{-1}$ and the concentrations were much lower than those of the total concentrations of the PFCAs and PFSAs (Table S3). Lower total concentrations of the precursors were observed in the effluent (average $=0.09 \mathrm{ng} \mathrm{L}^{-1}$ ) than in river water (average = $0.23 \mathrm{ng} \mathrm{L}^{-1}$ ) samples. Among the analyzed PFAA precursors, the FOSA was the most commonly detected compound with concentrations as high as $0.61 \mathrm{ng} \mathrm{L}^{-1}$ (site 22). The other three C8 precursors were not detected $\left(<0.06 \mathrm{ng} \mathrm{L}^{-1}\right)$ in the samples except for NMeFOSA, which was detected at site 1 . The low concentrations of the PFAA precursors and a relatively 
high concentration of FOSA were observed in studies by Motegi et al. (2013) and Zushi et al. (2011), which were conducted on the major rivers in Tokyo.

\subsection{Importance of PFAA precursors estimated by the oxidation of samples}

Oxidation treatment increased the average concentrations of total PFCAs by 6.5, 7.6, and 16 ng $\mathrm{L}^{-1}$ for upstream river water, downstream river water, and STP effluent samples, respectively (Table S3 and Figure 2b), which led to increased total concentrations of the PFAAs. The oxidation method converted PFCAs from both the PFCA and PFSA precursors, which were a potential source of PFAAs in river water. The concentrations of the PFCAs after oxidation treatment included the originally existed PFCAs as well as those formed from the oxidation of the precursors ( $\triangle[\mathrm{PFCAs}]$ ) (Figure 2c). The total concentrations of the PFCAs with 4-12 perfluoroalkyl carbon chains which were produced upon oxidation $(\Sigma \Delta[\mathrm{PFCA}$ C4-C12]) were 2.1 to $19 \mathrm{ng} \mathrm{L}^{-1}$ (average $=8.8 \mathrm{ng} \mathrm{L}^{-1}$, Table 1). As reported by Houtz and Sedlak (2012), the PFCAs with carbon chains containing more than 12 carbons did not noticeably increase. This indicated that the PFAA precursors with carbon chains containing more than 12 carbons were not present in the aquatic environment at a considerable level. Sulfonates are not formed from the oxidation of PFAA precursors (Houtz and Sedlak (2012). Although a slight increase in PFHxS (average of $0.3 \mathrm{ng} \mathrm{L}^{-1}$ ) was observed (Figure 2c), this was considered to be within the range of experimental error. It was indicated that the precursors of PFAAs having more than 12 carbons are present in aquatic environment at very low concentration level. The three most increased PFCAs were of the following order: PFHxA (average $\Delta[\mathrm{PFHxA}]=2.1 \mathrm{ng} \mathrm{L}^{-1}$ ) $>$ PFOA (average $\Delta[\mathrm{PFOA}]=1.9 \mathrm{ng} \mathrm{L}^{-1}$ ) $>$ PFBA (average $\Delta[\mathrm{PFBA}]=1.8 \mathrm{ng} \mathrm{L}^{-1}$ ) $($ Table 1$)$. The ratios of increased concentrations of the aforementioned PFCAs to the respective PFCA concentrations before oxidation ([PFAA $]_{\text {before }}$ oxidation) were $0.95,0.50$, and 1.2. The total concentrations of PFAAs were significantly different before and after oxidation $(p<0.05)$, indicating the existence of PFAA precursors in the environment. Thus, PFAA precursors cannot be neglected. Notably, the observed large percentage of $\Delta[\mathrm{PFBA}]$ among $\Delta[\mathrm{PFCA}]_{\mathrm{C} 4-\mathrm{C} 12}$ may be due to its shorter carbon chain lead to more formation from the various precursors with longer carbon chains (Figure 2c). In most of the samples, the $\Delta[\mathrm{PFCA}]_{\mathrm{C} 4-\mathrm{C} 12}$ by oxidation could not be explained by the degradation of the four PFAA precursors measured before oxidation.

The spatial distribution in river water is shown in Figure 2a-b. The increased concentrations of the PFCAs by oxidation $\left(\Sigma \Delta\right.$ PFCA $\left.\left._{\mathrm{C} 4-\mathrm{C} 12]}\right]\right)$ increased in the upstream along the river flow but did not change much in the middle to lower reach of the river. The concentrations of $\Sigma \Delta$ PFCA $\left._{\mathrm{C} 4-\mathrm{C} 12}\right]$ were $2.1-9.5 \mathrm{ng} \mathrm{L}^{-1}$, and the average concentrations of the main and branch river were 6.5 and $8.1 \mathrm{ng} \mathrm{L}^{-1}$, respectively (Table 1). At the sampling site 1, which was the most upstream site of the main river, the lowest concentrations of $\Sigma \Delta$ [PFCAs $\left.{ }_{\mathrm{C} 4-\mathrm{C} 12}\right]$ were observed, while the highest concentrations were observed in site 14 at the downstream of the main river. These results indicate that increased concentrations of the PFAA precursors exist in the middle to lower reach than the upstream of the river. 
While the concentrations of $\Sigma \Delta$ PFCA $\left._{\mathrm{C} 4-\mathrm{C} 12}\right]$ increased in the lower reach of the main river (Figure S2), the ratios of the PFCAs formed against PFAAs originally present $\left(\Sigma \Delta\right.$ PFCA $\left._{\mathrm{C} 4-\mathrm{C} 12]} / \Sigma[\mathrm{PFAAs}]_{\text {before oxidation }}\right)$ were much higher in the upstream of the main river and in the branch river ( 0.56 and 1.6 at sites 1 and 19, respectively) than the other sites of the river (Table 1 and Figure S2). According to Lei et al. (2004), this could be due to the existence of relatively important sources of PFAA precursors other than the STP effluents, such as untreated sewage in the upstream of the river, where the river water flow is less. A higher ratio was observed in upstream sites in mountainous areas where the temperature is lower than that in urban areas. Thus, the atmospheric deposition of volatile fluorinated precursors in water might be more predominant than that in urban areas. Notably, in the upstream of the Tama River, there is a large lake, which serves as a large surface for the deposition of volatile compounds. Furthermore, lower upstream concentrations could also explain why the deposition is larger than that downstream, where the overall PFCA concentration is higher. According to Ahrens et al. (2011), volatile precursors were emitted from the STPs and landfill sites to the atmosphere.

The difference in the ratios of individual PFCAs ( $\left.\triangle[\mathrm{PFCA}] /[\mathrm{PFCA}]_{\text {before oxidation }}\right)$ in all the upstream (sites 1, 3, 7, 19, 21, 22) and downstream (sites 9, 11, 13, 14, 16, 17) sites of the river and STP effluents (sites 23, 6, 12) are shown in Figure 3a-c and Table S4. For PFCAs with carbon chains containing 4 and 5 carbons, similar ratios were observed for all sites, while for PFCAs with chains containing 6 to 9 carbons, the ratios decreased significantly $(p<$ 0.05) from the upstream to downstream sites. These results implied that there could be different sources of PFAA precursors with different carbon chain lengths.

The concentrations of $\Sigma \Delta$ PFCA $\left._{\mathrm{C} 4-\mathrm{C} 12}\right]$ in the $3 \mathrm{STP}$ effluent samples (site 23, 6, 12) were 18, 11, and $19 \mathrm{ng} \mathrm{L}^{-1}$ (average $=16 \mathrm{ng} \mathrm{L} \mathrm{L}^{-1}$ ), respectively (Table 1). Increased concentrations of $\Sigma \Delta\left[\mathrm{PFCA}_{\mathrm{C} 4-\mathrm{C} 12}\right]$ were observed in the STP effluents compared to the river water samples (Figure 3). These results indicated that the STP effluents were one of the major sources of the PFAA precursors in the aquatic environment. However, the ratios of $\Sigma \Delta\left[\mathrm{PFCA}_{\mathrm{C} 4-\mathrm{C} 12}\right]$ to $\Sigma\left[\mathrm{PFCA}_{\mathrm{C} 4-\mathrm{C} 12}\right]_{\text {before oxidation }}$ in the $\mathrm{STP}$ effluents (average $=0.21$ ) were slightly lower than those in the river water samples (average of main river $=0.28$ and branch river $=0.69)($ Figure 3 and Table 1), whereas the differences were not statistically significant $(p>0.05)$. The elevated concentration and the lower ratios of $\Sigma \Delta\left[\mathrm{PFCA}_{\mathrm{C} 4-\mathrm{C} 12}\right]$ in the STP effluents indicated the degradation of precursors during the sewage treatment process. This observation supported the studies by Shivakoti et al. (2010) and Sun et al. (2012), which showed the increase of PFAAs during the sewage treatment process.

The average ratios of $\Sigma \Delta$ PFCA $\left._{\mathrm{C} 4-\mathrm{C} 12]}\right]$ in the river water samples were 0.28 and 0.69 for the main and branch rivers, respectively. These ratios were much higher than that of the previous studies by Benskin et al. (2012), Motegi et al. (2013), Murakami et al. (2009), and Zushi et al. (2011) on aquatic environment in which the individual precursors were determined. Hence, it can be concluded that the previous studies underestimated the 
occurrence of the PFAA precursors in the aquatic environment and that a greater number of precursors beyond the commonly measured ones existed.

\section{Conclusion}

To our knowledge, this is the first study regarding the spatial distribution of total PFAA precursors in urban river water and STP effluents. The importance of PFAA precursors in river water and STP effluent samples were revealed by the significant difference in the total concentrations of PFAAs before and after oxidation $(p<0.05)$. Therefore, the commonly measured precursors were only a part of the total precursors present in the environment. The

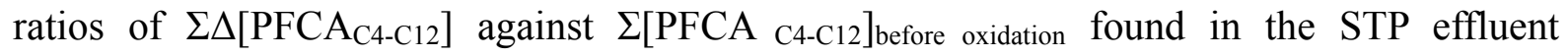
samples were lower (average $=0.21$ ) than those found in the river water (average $=0.28$ and 0.69) samples, which implied that the precursors might have decomposed into PFAAs during the sewage treatment process. On the other hand, higher ratios were observed in the upstream water samples which indicated the existence of emission sources other than the STP effluents. This study showed that although the treatment process converting a part of the PFAA precursors into PFAAs, STPs were important sources of precursors to the Tama River. Further studies on the original sources of precursors are required to reduce the emission of PFAAs and their PFAA precursors in the aquatic environment.

\section{Acknowledgements}

The authors are grateful for financial support by the River Fund for Young Scientists Grant (25-1263-008) from the River Foundation, Japan, and the Leadership Program in Sustainable Living with Environmental Risk (SLER) at Yokohama National University under the aid of Strategic Funds for the Promotion of Science and Technology from the Ministry of Education, Culture, Sports, Science and Technology. Furthermore, we are thankful for the kind help by Makoto Sekine and Mohammad Raknuzzaman during field sampling and by Yaeko Goto in laboratory.

\section{Supplementary information}

Additional text, tables and figures. This material is available free of charge via the Internet $\underline{\text { http://www.sciencedirect.com. }}$

\section{REFERENCES}

Ahrens, L., Shoeib, M., Harner, T., Lee, S.C., Guo, R., Reiner, E.J., 2011. Wastewater Treatment Plant and Landfills as Sources of Polyfluoroalkyl Compounds to the Atmosphere†. Environ. Sci. Technol. 45, 8098-8105. doi:10.1021/es1036173

Benskin, J.P., Ikonomou, M.G., Gobas, F.A.P.C., Woudneh, M.B., Cosgrove, J.R., 2012. Observation of a Novel PFOS-Precursor, the Perfluorooctane Sulfonamido Ethanol-Based Phosphate (SAmPAP) Diester, in Marine Sediments. Environ. Sci. 
Technol. 46, 6505-6514. doi:10.1021/es300823m

Buck, R.C., Franklin, J., Berger, U., Conder, J.M., Cousins, I.T., de Voogt, P., Jensen, A.A., Kannan, K., Mabury, S.A., van Leeuwen, S.P., 2011. Perfluoroalkyl and Polyfluoroalkyl Substances in the Environment: Terminology, Classification, and Origins. Integr. Environ. Assess. Manag. 7, 513-541. doi:10.1002/ieam.258

Bureau of Sewerage, Tokyo Metropolitan Government, 2012. Overview of works of Bureau of Sewerage Tokyo Metropolitan Government, 2012. Bureau of Sewerage, Tokyo Metropolitan Government.

Butt, C.M., Muir, D.C.G., Mabury, S.A., 2014. Biotransformation pathways of fluorotelomer-based polyfluoroalkyl substances: A review. Environ. Toxicol. Chem. 33, 243-267. doi:10.1002/etc. 2407

Butt, C.M., Muir, D.C.G., Stirling, I., Kwan, M., Mabury, S.A., 2007. Rapid Response of Arctic Ringed Seals to Changes in Perfluoroalkyl Production. Environ. Sci. Technol. 41, 42-49. doi:10.1021/es061267mD'eon, J.C., Mabury, S.A., 2007. Production of Perfluorinated Carboxylic Acids (PFCAs) from the Biotransformation of Polyfluoroalkyl Phosphate Surfactants (PAPS): Exploring Routes of Human Contamination. Environ. Sci. Technol. 41, 4799-4805. doi:10.1021/es070126x

De Silva, A.O., Allard, C.N., Spencer, C., Webster, G.M., Shoeib, M., 2012. Phosphorus-Containing Fluorinated Organics: Polyfluoroalkyl Phosphoric Acid Diesters (diPAPs), Perfluorophosphonates (PFPAs), and Perfluorophosphinates (PFPIAs) in Residential Indoor Dust. Environ. Sci. Technol. 46, 12575-12582. doi:10.1021/es303172p

Gauthier, S.A., Mabury, S.A., 2005. Aqueous photolysis of 8:2 fluorotelomer alcohol. Environ. Toxicol. Chem. 24, 1837-1846. doi:10.1897/04-591R.1

Gewurtz, S.B., Backus, S.M., De Silva, A.O., Ahrens, L., Armellin, A., Evans, M., Fraser, S., Gledhill, M., Guerra, P., Harner, T., Helm, P.A., Hung, H., Khera, N., Kim, M.G., King, M., Lee, S.C., Letcher, R.J., Martin, P., Marvin, C., McGoldrick, D.J., Myers, A.L., Pelletier, M., Pomeroy, J., Reiner, E.J., Rondeau, M., Sauve, M.-C., Sekela, M., Shoeib, M., Smith, D.W., Smyth, S.A., Struger, J., Spry, D., Syrgiannis, J., Waltho, J., 2013. Perfluoroalkyl acids in the Canadian environment: Multi-media assessment of current status and trends. Environ. Int. 59, 183-200. doi:10.1016/j.envint.2013.05.008

Hart, K., Gill, V.A., Kannan, K., 2009. Temporal Trends (1992-2007) of Perfluorinated Chemicals in Northern Sea Otters (Enhydra lutris kenyoni) from South-Central Alaska. Arch. Environ. Contam. Toxicol. 56, 607-614. doi:10.1007/s00244-008-9242-2

Houtz, E.F., Sedlak, D.L., 2012. Oxidative Conversion as a Means of Detecting Precursors to Perfluoroalkyl Acids in Urban Runoff. Environ. Sci. Technol. 46, 9342-9349. doi:10.1021/es302274g

Lee, H., Tevlin, A.G., Mabury, S.A., Mabury, S.A., 2014. Fate of Polyfluoroalkyl Phosphate 
Diesters and Their Metabolites in Biosolids-Applied Soil: Biodegradation and Plant Uptake in Greenhouse and Field Experiments. Environ. Sci. Technol. 48, 340-349. doi:10.1021/es403949z

Lei, Y.D., Wania, F., Mathers, D., Mabury, S.A., 2004. Determination of Vapor Pressures, Octanol-Air, and Water-Air Partition Coefficients for Polyfluorinated Sulfonamide, Sulfonamidoethanols, and Telomer Alcohols. J. Chem. Eng. Data 49, 1013-1022. doi:10.1021/je049949h

Long, M., Bossi, R., Bonefeld-J?rgensen, E.C., 2012. Level and temporal trend of perfluoroalkyl acids in Greenlandic Inuit. Int. J. Circumpolar Health 71. doi:10.3402/ijch.v71i0.17998

Martin, J.W., Asher, B.J., Beesoon, S., Benskin, J.P., Ross, M.S., 2010. PFOS or PreFOS? Are perfluorooctane sulfonate precursors (PreFOS) important determinants of human and environmental perfluorooctane sulfonate (PFOS) exposure? J. Environ. Monit. 12, 1979-2004. doi:10.1039/C0EM00295J

Motegi, M., Nojiri, K., Hosono, S., 2013. Investigation of PFOS, PFOA and their precursor pollution in rivers of Saitama prefectre (No. 10). Center for Environmental Science in Saitama.

Murakami, M., Imamura, E., Shinohara, H., Kiri, K., Muramatsu, Y., Harada, A., Takada, H., 2008. Occurrence and Sources of Perfluorinated Surfactants in Rivers in Japan. Environ. Sci. Technol. 42, 6566-6572. doi:10.1021/es800353f

Murakami, M., Shinohara, H., Takada, H., 2009. Evaluation of wastewater and street runoff as sources of perfluorinated surfactants (PFSs). Chemosphere 74, 487-493. doi:10.1016/j.chemosphere.2008.10.018

Olsen, G.W., Lange, C.C., Ellefson, M.E., Mair, D.C., Church, T.R., Goldberg, C.L., Herron, R.M., Medhdizadehkashi, Z., Nobiletti, J.B., Rios, J.A., Reagen, W.K., Zobel, L.R., 2012. Temporal Trends of Perfluoroalkyl Concentrations in American Red Cross Adult Blood Donors, 2000-2010. Environ. Sci. Technol. 46, 6330-6338. doi:10.1021/es300604p

Plumlee, M.H., McNeill, K., Reinhard, M., 2009. Indirect Photolysis of Perfluorochemicals: Hydroxyl Radical-Initiated Oxidation of N-Ethyl Perfluorooctane Sulfonamido Acetate (N-EtFOSAA) and Other Perfluoroalkanesulfonamides. Environ. Sci. Technol. 43, 3662-3668. doi:10.1021/es803411w

Reiner, J.L., O’Connell, S.G., Moors, A.J., Kucklick, J.R., Becker, P.R., Keller, J.M., 2011. Spatial and Temporal Trends of Perfluorinated Compounds in Beluga Whales (Delphinapterus leucas) from Alaska. Environ. Sci. Technol. 45, 8129-8136. doi:10.1021/es103560q

Rhoads, K.R., Janssen, E.M.-L., Luthy, R.G., Criddle, C.S., 2008. Aerobic Biotransformation and Fate of N-Ethyl Perfluorooctane Sulfonamidoethanol (N-EtFOSE) in Activated Sludge. Environ. Sci. Technol. 42, 2873-2878. doi:10.1021/es702866c 
Shivakoti, B.R., Tanaka, S., Fujii, S., Kunacheva, C., Boontanon, S.K., Musirat, C., Seneviratne, S.T.M.L.D., Tanaka, H., 2010. Occurrences and behavior of perfluorinated compounds (PFCs) in several wastewater treatment plants (WWTPs) in Japan and Thailand. J. Environ. Monit. 12, 1255-1264. doi:10.1039/B927287A

Sun, H., Zhang, X., Wang L-1., Zhang, T., Li, F., He, N., Alder, A.C., 2012. Perfluoroalkyl compounds in municipal WWTPs in Tianjin, China-concentrations, distribution and mass flow. Environ. Sci. Pollut. Res. 19, 1405-1415. doi:10.1007/s11356-011-0727-6

Taniyasu, S., Kannan, K., So, M.K., Gulkowska, A., Sinclair, E., Okazawa, T., Yamashita, N., 2005. Analysis of fluorotelomer alcohols, fluorotelomer acids, and short- and long-chain perfluorinated acids in water and biota. J. Chromatogr. A 1093, 89-97. doi:10.1016/j.chroma.2005.07.053

Trier, X., Granby, K., Christensen, J., 2011. Polyfluorinated surfactants (PFS) in paper and board coatings for food packaging. Environ. Sci. Pollut. Res. 18, 1108-1120. doi:10.1007/s11356-010-0439-3

Tsao, M.-S., Wilmarth, W.K., 1959. The Aqueous Chemistry of Inorganic Free Radicals. I. The Mechanism of the Photolytic Decomposition of Aqueous Persulfate Ion and Evidence Regarding the Sulfate-Hydroxyl Radical Interconversion Equilibrium. J. Phys. Chem. 63, 346-353. doi:10.1021/j150573a006

Xu, L., Krenitsky, D.M., Seacat, A.M., Butenhoff, J.L., Anders, M.W., 2004. Biotransformation of N-Ethyl-N-(2-hydroxyethyl)perfluorooctanesulfonamide by Rat Liver Microsomes, Cytosol, and Slices and by Expressed Rat and Human Cytochromes P450. Chem. Res. Toxicol. 17, 767-775. doi:10.1021/tx034222x

Zushi, Y., Masunaga, S., 2011. GIS-based source identification and apportionment of diffuse water pollution: Perfluorinated compound pollution in the Tokyo Bay basin. Chemosphere 85, 1340-1346. doi:10.1016/j.chemosphere.2011.07.052

Zushi, Y., Ye, F., Motegi, M., Nojiri, K., Hosono, S., Suzuki, T., Kosugi, Y., Yaguchi, K., Masunaga, S., 2011. Spatially Detailed Survey on Pollution by Multiple Perfluorinated Compounds in the Tokyo Bay Basin of Japan. Environ. Sci. Technol. 45, 2887-2893. doi:10.1021/es103917r 


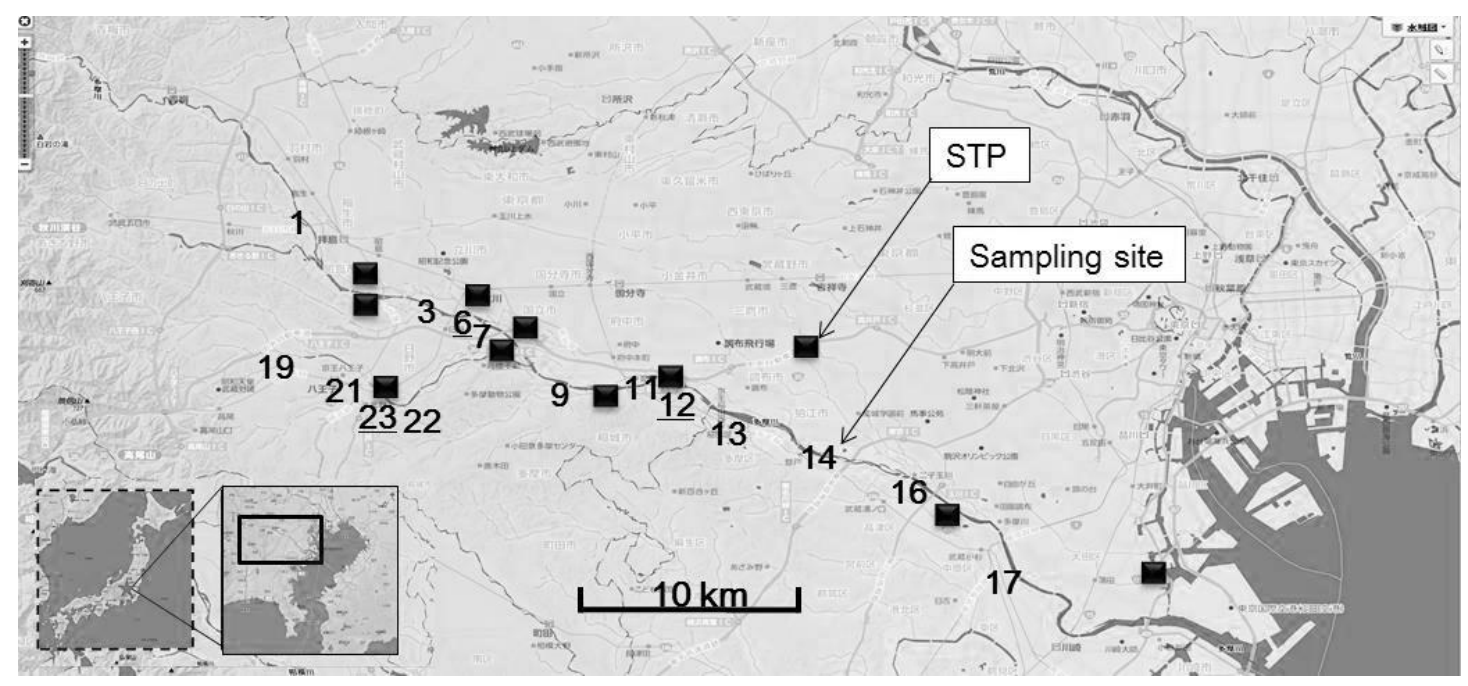

Fig. 1 Map of the Tama River and sampling locations.

Squares represent sewage treatment plants (STPs). The underlined numbers represent STP effluent sampling sites, and non-underlined numbers represent river water sampling sites. 

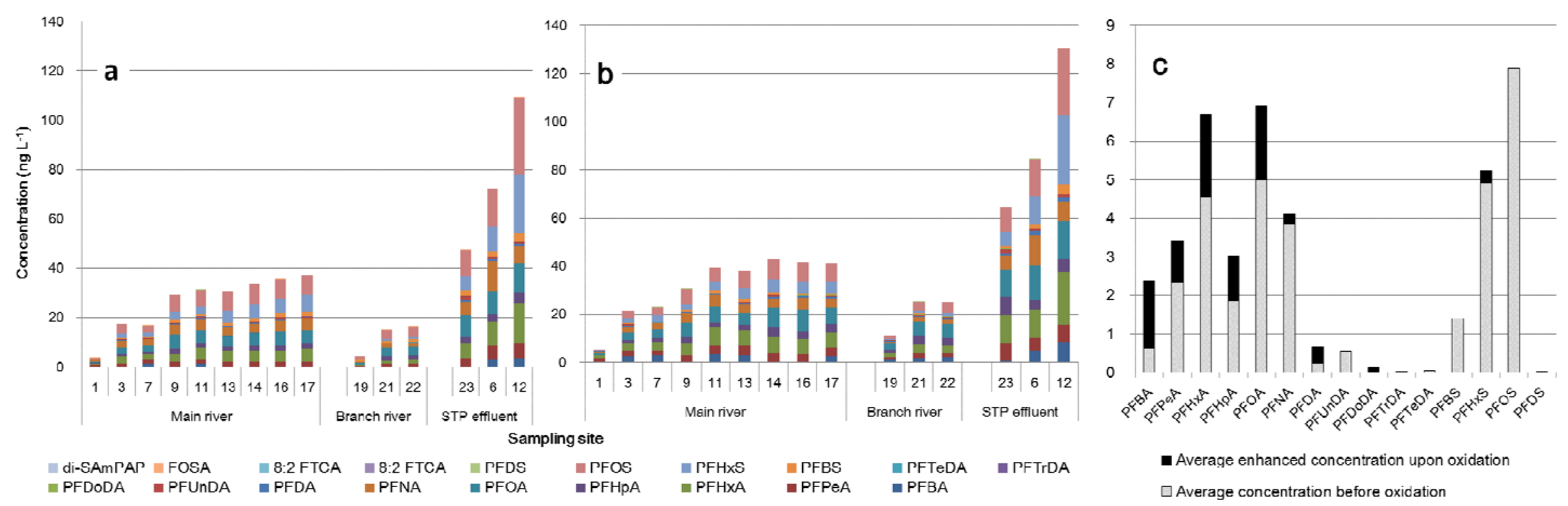

Fig. 2 Concentration of perfluoroalkyl acids (PFAAs) before and after oxidation (ng $\left.\mathrm{L}^{-1}\right)$.

a) PFAAs $(n=16)$ and their precursors $(n=3)$ before oxidation in all sampling sites.

b) PFAAs and their precursors after oxidation in all sampling sites.

c) Average concentration of individual PFAA in all sampling sites; the gray bars represent the average concentrations before oxidation and black bars represent the increase in the concentration after oxidation. 


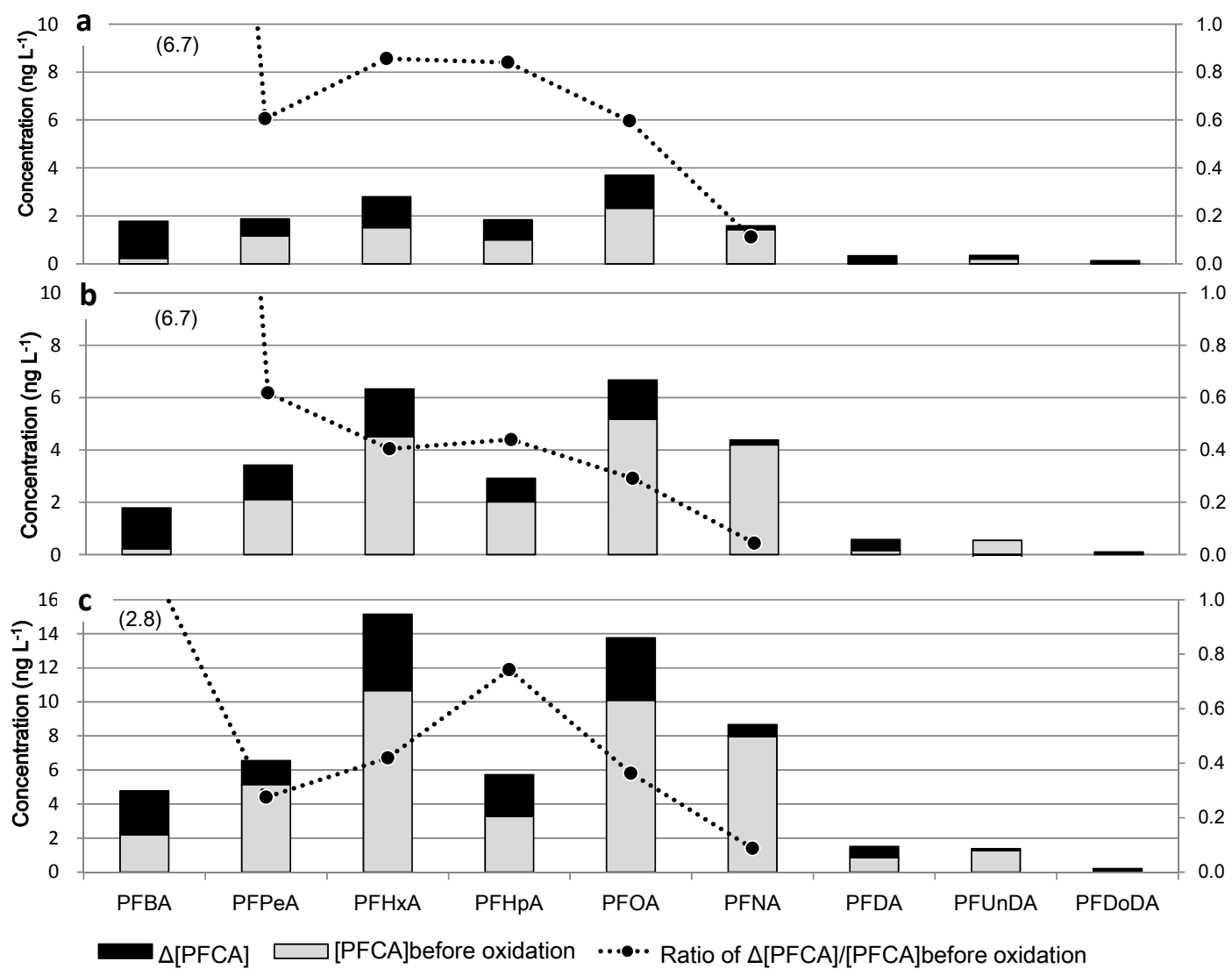

Fig. 3 Average concentrations (ng $\mathrm{L}^{-1}$ ) of perfluorinated carboxylic acids before

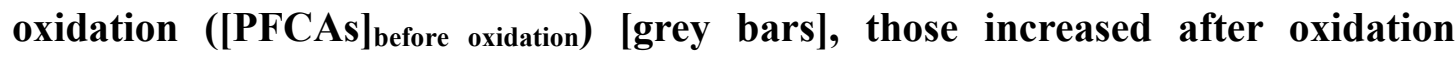
( $\triangle$ [PFCAs]) [black bars], and the ratio of their concentrations ( $\Delta$ [PFCAs] / [PFCAs $]_{\text {before oxidation) [line graph]. }}$

a) Upstream river water samples (average of sites 1, 3, 7, 19, 21, and 22).

b) Downstream river water samples (average of sites 9, 11, 13, 14, 16, and 17).

c) Sewage treatment plant effluent samples (average of sites 6, 12, and 23). 
Table 1. Increased concentration of perfluorinated carboxylic acids (PFCAs, ng L $^{-1}$ ) upon oxidation of PFAA precursors in samples; the ratio of increased total PFCAs to perfluoroalkyl acids (LPFAAs) before oxidation; and the ratio of increased individual PFCA to PFCA before oxidation.

\begin{tabular}{|c|c|c|c|c|c|c|c|c|c|c|c|c|c|c|c|c|c|c|c|c|c|c|c|}
\hline \multirow{2}{*}{$\begin{array}{l}\text { River water } \\
\text { / STP } \\
\text { effluent } \\
\end{array}$} & \multirow{2}{*}{$\begin{array}{l}\text { Main / } \\
\text { Branch }\end{array}$} & \multicolumn{12}{|c|}{ Increased concentration of PFCAs by oxidation of PFAA precursors } & \multirow{2}{*}{$\begin{array}{c}\text { Ratio of } \\
\Sigma \Delta\left[\text { PFCA }{ }_{C 4-\mathrm{C} 12]}\right] \\
\Sigma[\text { PFAAs }]_{\text {before oxidation }}\end{array}$} & \multicolumn{9}{|c|}{ Ratio of $\Delta[\mathrm{PFCA}] /[\mathrm{PFCA}]_{\text {before oxidation }}$} \\
\hline & & $\begin{array}{c}\text { Sampling } \\
\text { sites }\end{array}$ & $\Delta[\mathrm{PFBA}]$ & $\Delta[\mathrm{PFPeA}]$ & $\Delta[\mathrm{PFHxA}]$ & $\Delta[\mathrm{PFHpA}]$ & $\Delta[\mathrm{PFOA}]$ & $\Delta[\mathrm{PFNA}]$ & $\Delta[\mathrm{PFDA}]$ & $\Delta[$ PFUnDA $]$ & $\Delta[$ PFDoDA $]$ & $\begin{array}{c}\Sigma \Delta[\mathrm{PFCA} \\
\mathrm{C} 4-\mathrm{C} 12] \\
\end{array}$ & $\begin{array}{l}\Sigma[\text { PFAAs }] \\
\text { Before oxidation }\end{array}$ & & PFBA & PFPeA & PFHxA & PFHрA & PFOA & PFNA & PFDA & PFUnDA & PFDoDA \\
\hline \multirow{14}{*}{$\begin{array}{l}\text { River } \\
\text { water }\end{array}$} & \multirow{9}{*}{$\begin{array}{l}\text { Main } \\
\text { river }\end{array}$} & 1 & 0.32 & 0.52 & 0.73 & $<0.01$ & 0.51 & $<0.01$ & $<0.01$ & $<0.01$ & $<0.01$ & 2.1 & 3.7 & 0.56 & - & 0.71 & 0.89 & 0 & 0.87 & 0 & - & 0 & - \\
\hline & & 3 & 2.6 & 0.54 & 0.78 & 0.15 & 0.32 & $<0.01$ & $<0.01$ & 0.17 & $<0.01$ & 4.6 & 17 & 0.26 & - & 0.33 & 0.30 & 0.16 & 0.11 & 0 & 0 & 0.36 & - \\
\hline & & 7 & 1.4 & 0.74 & 1.2 & 0.52 & 1.4 & $<0.01$ & $<0.01$ & $<0.01$ & $<0.01$ & 5.2 & 17 & 0.31 & 1.0 & 0.52 & 0.46 & 0.51 & 0.55 & 0 & 0 & 0 & - \\
\hline & & 9 & 0.47 & 0.43 & 1.5 & 0.78 & $<0.01$ & 0.12 & 0.29 & $<0.01$ & $<0.01$ & 3.6 & 29 & 0.12 & - & 0.21 & 0.46 & 0.35 & 0 & 0.03 & 1.5 & 0 & - \\
\hline & & 11 & 2.4 & 1.5 & 2.5 & 0.38 & 1.5 & 0.52 & 0.46 & $<0.01$ & $<0.01$ & 9.2 & 31 & 0.29 & 1.8 & 0.89 & 0.49 & 0.22 & 0.29 & 0.11 & 2.0 & 0 & - \\
\hline & & 13 & 3.3 & 1.5 & 1.8 & 0.71 & 0.40 & 0.47 & 0.23 & 0.04 & $<0.01$ & 8.5 & 30 & 0.28 & - & 0.64 & 0.41 & 0.45 & 0.09 & 0.14 & 1.2 & 0.09 & - \\
\hline & & 14 & 0.40 & 1.8 & 2.0 & 1.3 & 2.9 & 0.54 & 0.42 & $<0.01$ & $<0.01$ & 9.5 & 34 & 0.28 & - & 0.85 & 0.43 & 0.61 & 0.59 & 0.15 & 2.9 & 0 & - \\
\hline & & 16 & $<0.01$ & 1.4 & 1.7 & 1.2 & 3.0 & 0.42 & 0.56 & $<0.01$ & $<0.01$ & 8.2 & 5 & 0.23 & 1.4 & 0.66 & 0.37 & 0.54 & 0.53 & 0.09 & 3.2 & 0 & - \\
\hline & & 17 & 2.7 & 1.2 & 1.4 & 0.96 & 1.3 & $<0.01$ & $<0.01$ & 0.21 & $<0.01$ & 7.8 & 37 & 0.21 & - & 0.53 & 0.29 & 0.43 & 0.24 & 0 & 0 & 0.51 & - \\
\hline & \multicolumn{2}{|c|}{ Average } & 1.5 & 1.1 & 1.5 & 0.67 & 1.3 & 0.23 & 0.22 & 0.05 & $<0.01$ & 6.5 & 26 & 0.28 & 1.4 & 0.59 & 0.45 & 0.36 & 0.36 & 0.06 & 1.3 & 0.11 & - \\
\hline & \multirow{3}{*}{$\begin{array}{l}\text { Branch } \\
\text { river }\end{array}$} & 19 & 0.95 & 0.69 & 1.6 & 1.3 & 1.6 & 0.56 & $<0.01$ & $<0.01$ & $<0.01$ & 6.6 & 4.1 & 1.60 & - & 1.5 & 6.2 & 6.3 & 1.8 & 2.1 & - & - & - \\
\hline & & 21 & 2.0 & 1.1 & 2.0 & 1.8 & 2.2 & $<0.01$ & $<0.01$ & 0.38 & $<0.01$ & 9.4 & 15 & 0.63 & - & 0.91 & 1.5 & 1.0 & 0.58 & 0 & - & 2.4 & - \\
\hline & & 22 & 2.0 & 0.64 & 1.5 & 1.5 & 2.3 & 0.34 & $<0.01$ & $<0.01$ & $<0.01$ & 8.3 & 16 & 0.51 & - & 0.42 & 1.0 & 0.79 & 0.69 & 0.23 & - & 0 & - \\
\hline & \multicolumn{2}{|c|}{ Average } & 1.6 & 0.81 & 1.7 & 1.5 & 2.0 & 0.30 & $<0.01$ & 0.13 & $<0.01$ & 8.1 & 12 & 0.69 & - & 0.93 & 2.9 & 2.7 & 1.0 & 0.78 & - & 1.2 & - \\
\hline \multirow{4}{*}{$\begin{array}{c}\text { STP } \\
\text { effluent }\end{array}$} & & 23 & 0.80 & 3.7 & 5.7 & 4.8 & 2.4 & 0.40 & 0.30 & 0.18 & $<0.01$ & 18 & 48 & 0.38 & - & 1.0 & 0.98 & 1.7 & 0.26 & 0.08 & 0.44 & 0.12 & - \\
\hline & & 6 & 1.6 & $<0.01$ & 2.1 & 1.3 & 4.9 & 0.66 & 0.93 & $<0.01$ & $<0.01$ & 11 & 72 & 0.16 & 0.50 & 0 & 0.22 & 0.43 & 0.53 & 0.06 & 1.1 & 0 & - \\
\hline & & 12 & 5.3 & 0.99 & 5.6 & 1.3 & 3.7 & 1.0 & 0.69 & 0.49 & $<0.01$ & 19 & 109 & 0.18 & 1.6 & 0.16 & 0.34 & 0.32 & 0.31 & 0.15 & 0.68 & 0.47 & - \\
\hline & \multicolumn{2}{|c|}{ Average } & 2.6 & 1.5 & 4.5 & 2.4 & 3.7 & 0.70 & 0.64 & 0.22 & $<0.01$ & 16 & 76 & 0.21 & 1.0 & 0.39 & 0.51 & 0.80 & 0.37 & 0.10 & 0.74 & 0.20 & - \\
\hline $\begin{array}{l}\text { River \& } \\
\text { effluent }\end{array}$ & \multicolumn{2}{|c|}{ Average } & 1.8 & 1.1 & 2.1 & 1.2 & 1.9 & 0.34 & 0.26 & 0.10 & $<0.01$ & 8.8 & 33 & 0.40 & 1.2 & 0.62 & 0.95 & 0.92 & 0.50 & 0.21 & 1.2 & 0.28 & - \\
\hline
\end{tabular}

To calculate the ratio of $\Delta[\mathrm{PFCA}] /[\mathrm{PFCA}]_{\text {before oxidation }}$ and average concentration, $<$ LOD was assume to be 0 .

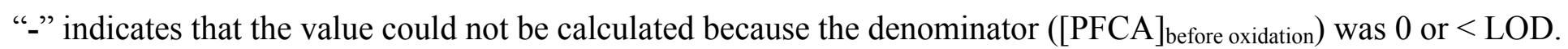




\section{Supplementary information}

Table S1. Sampling site information.

\begin{tabular}{clccc}
\hline $\begin{array}{c}\text { Sample } \\
\text { ID }\end{array}$ & \multicolumn{1}{c}{ Type of Sampling site } & $\begin{array}{c}\text { Sampling } \\
\text { time }\end{array}$ & $\begin{array}{c}\text { Sampling } \\
\text { place in } \\
\text { river }\end{array}$ & $\begin{array}{c}\text { Location in World } \\
\text { Geodetic System }\end{array}$ \\
\hline 1 & Main river & $13: 30$ & center & $35.732429,139.32106$ \\
3 & Main river & $14: 05$ & center & $35.694145,139.373864$ \\
7 & Main river & $15: 52$ & left & $35.67391,139.427229$ \\
9 & Main river & $16: 15$ & center & $35.658534,139.439353$ \\
11 & Main river & $16: 40$ & center & $35.652414,139.488169$ \\
13 & Main river & $17: 19$ & center & $35.64408,139.525613$ \\
14 & Main river & $17: 53$ & center & $35.62507,139.568593$ \\
16 & Main river & $18: 43$ & right & $35.600297,139.638955$ \\
17 & Main river & $19: 10$ & center & $35.58545,139.668808$ \\
\hline 19 & Branch river & $13: 03$ & center & $35.680324,139.300136$ \\
21 & Branch river & $12: 08$ & center & $35.666989,139.337866$ \\
22 & Branch river & $11: 45$ & center & $35.655821,139.355996$ \\
\hline 23 & STP effluent flowing into a branch river & $11: 24$ & center & $35.655126,139.355167$ \\
6 & STP effluent flowing into the main river & $14: 39$ & center & $35.685178,139.410321$ \\
12 & STP effluent flowing into the main river & $17: 06$ & center & $35.654193,139.512459$ \\
\hline
\end{tabular}


Table S2. Abbreviations of perfluoroalkyl acids, their precursors, and their suppliers.

\begin{tabular}{|c|c|c|c|}
\hline Classification & Abbreviation & Compound name & Supplier of standard and its purity \\
\hline \multirow{14}{*}{$\begin{array}{l}\text { PFCAs (perfluoroalkyl } \\
\text { carboxylic acids) }\end{array}$} & PFBA & Perfluorobutanoate & \multirow{11}{*}{$\begin{array}{l}\text { PFC-MXA } \\
\text { Wellington Laboratories, 98\% }\end{array}$} \\
\hline & PFPeA & Perfluoropentanoate & \\
\hline & PFHxA & Perfluorohexanoate & \\
\hline & PFHpA & Perfluoroheptanoate & \\
\hline & PFOA & Perfluorooctanoate & \\
\hline & PFNA & Perfluorononanoate & \\
\hline & PFDA & Perfluorodecanoate & \\
\hline & PFUnDA & Perfluoroundecanoate & \\
\hline & PFDoDA & Perfluorododecanoate & \\
\hline & PFTrDA & Perfluorotridecanoate & \\
\hline & PFTeDA & Perfluorotetradecanoate & \\
\hline & {$\left[{ }^{13} \mathrm{C} 2\right] \mathrm{PFHxA}$} & Perfluoro-n- $\left[1,2-{ }^{13} \mathrm{C} 2\right]$ hexanoate & Wellington Laboratories, $98 \%$ \\
\hline & {$\left[{ }^{13} \mathrm{C} 4\right] \mathrm{PFOA}$} & Perfluoro-n- $\left[1,2,3,4-{ }^{13} \mathrm{C} 4\right]$ octanoate & Wellington Laboratories, $98 \%$ \\
\hline & {$\left[{ }^{13} \mathrm{C} 2\right]$ PFDoDA } & Perfluoro-n-[1,2- $\left.{ }^{13} \mathrm{C} 2\right]$ dodecanoate & Wellington Laboratories, 98\% \\
\hline \multirow{5}{*}{$\begin{array}{l}\text { PFSAs (perfluoroalkyl } \\
\text { sulfonic acids) }\end{array}$} & PFBS & Perfluorobutane sulfonate & Tokyo Chemical Ind., 98\% \\
\hline & PFHxS & Perfluorohexane sulfonate & Wellington Laboratories, 98\% \\
\hline & PFOS & Perfluorooctane sulfonate & Kanto Chemical, 98\% including branched isomer \\
\hline & PFDS & Perfluorodecane sulfonate & Wellington Laboratories, $98 \%$ \\
\hline & {$\left[{ }^{13} \mathrm{C} 4\right] \mathrm{PFOS}$} & perfluoro-1-[1,2,3,4-13 $\mathrm{C} 4]$ octanesulfonate & Wellington Laboratories, 98\% \\
\hline \multirow{2}{*}{$\begin{array}{l}\text { FTCAs (Fluorotelomer } \\
\text { carboxylates) }\end{array}$} & $8: 2$ FTCA & 2-perfluorooctylethanoate & Wellington Laboratories, 98\% \\
\hline & {$\left[{ }^{13} \mathrm{C} 2\right] 8: 2 \mathrm{FTCA}$} & 2-perfluorooctyl-[1,2- $\left.{ }^{13} \mathrm{C} 2\right]$-ethanoate & Wellington Laboratories, 98\% \\
\hline \multirow{4}{*}{$\begin{array}{l}\text { FOSAs (Perfluorooctane } \\
\text { sulfonamides) }\end{array}$} & NMeFOSA & N-methylperfluoro-1-octanesulfonamide & Wellington Laboratories, 98\% \\
\hline & FOSA & Perfluorooctane sulfoneamide & Wellington Laboratories, 98\% \\
\hline & {$\left[{ }^{13} \mathrm{C} 8\right] \mathrm{FOSA}$} & Perfluoro-1-[ $\left[{ }^{13} \mathrm{C} 8\right]$-octane sulfoneamide & Wellington Laboratories, $98 \%$ \\
\hline & d5-NEtFOSA & N-deuterioethylperfluoro-1-octanesulfonamide & Wellington Laboratories, 98\% \\
\hline \multirow{2}{*}{$\begin{array}{l}\text { Polyfluorinated Phosphate } \\
\text { Esters }\end{array}$} & SAm-PAP & Bis (N-ethyl perfluorooctane sulfonamido ethanol) phosphate & Industry material, $90 \%$ \\
\hline & {$\left[{ }^{13} \mathrm{C} 4\right] 8: 2 \operatorname{diPAP}$} & ${ }^{13} \mathrm{C} 4-\mathrm{Bis}(1 \mathrm{H}, 1 \mathrm{H}, 2 \mathrm{H}, 2 \mathrm{H}$ perfluorooctyl phosphate & Wellington Laboratories, 98\% \\
\hline
\end{tabular}




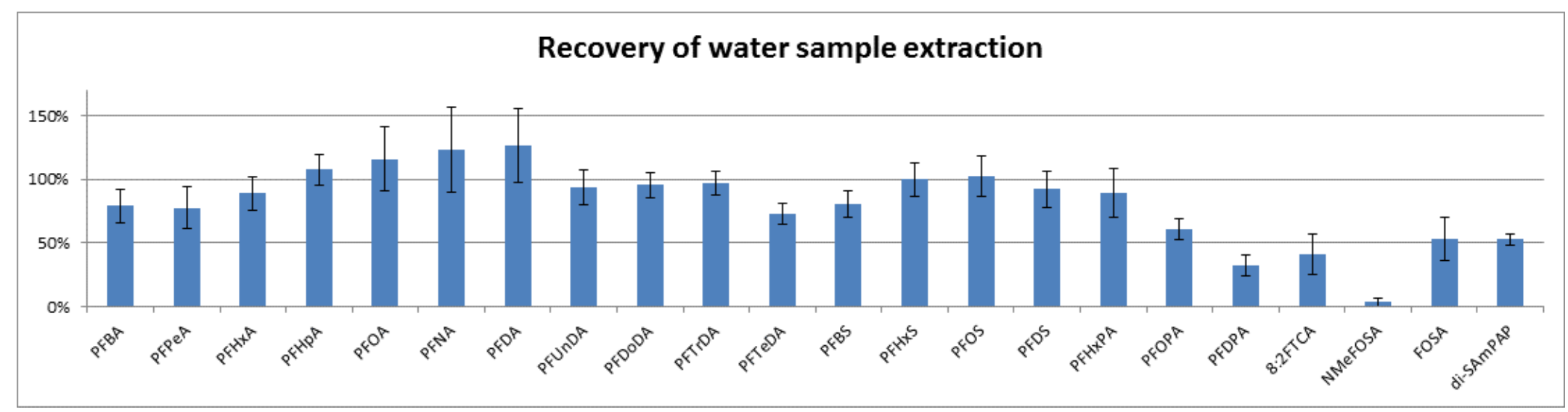

Figure S1. Recovery rates of spiked chemicals in water samples for solid-phase extraction ( $\mathrm{n}=3$ ); Error bars represent the standard deviation.

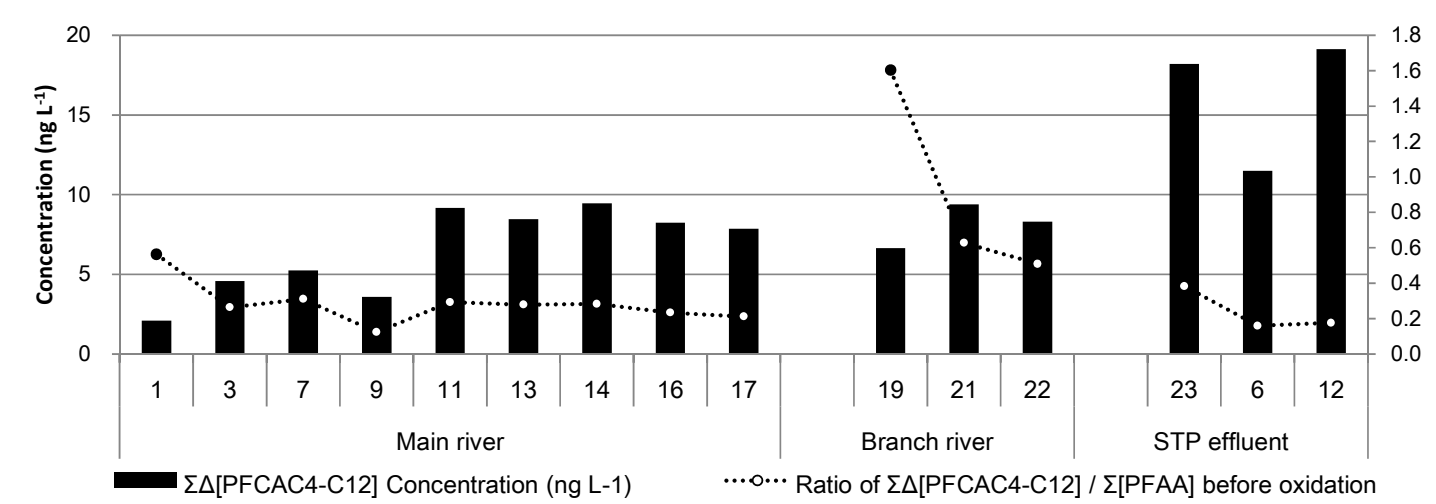

Figure S2. Total perfluorinated carboxylic acid concentrations formed upon oxidation (ng $\left.L^{-1}\right)\left(\Sigma \Delta\left[P F C A A_{C 4-C 12}\right]\right)$ and the ratio of their concentration to that of the total perfluoroalkyl acids before oxidation ( $\Sigma[\mathrm{PFAA}]_{\text {before oxidation). }}$ 
Table S3. Concentration of perfluoroalkyl acids and their precursors in river water and sewage treatment plant effluent samples before and after oxidation (ng $\left.\mathbf{L}^{-1}\right)$.

\begin{tabular}{|c|c|c|c|c|c|c|c|c|c|c|c|c|c|c|c|c|c|c|c|c|c|c|c|c|}
\hline \multirow{2}{*}{$\begin{array}{l}\text { Before / After } \\
\text { oxidation }\end{array}$} & \multirow{2}{*}{$\begin{array}{l}\text { River water / } \\
\text { STP effluent }\end{array}$} & \multirow{2}{*}{$\begin{array}{l}\text { Main/ } \\
\text { Branch }\end{array}$} & \multirow{2}{*}{$\begin{array}{l}\text { Sampling } \\
\text { sites }\end{array}$} & \multicolumn{16}{|c|}{ PFAAs } & \multicolumn{4}{|c|}{ PFAA precursros } & \multirow{2}{*}{ Total } \\
\hline & & & & PFBA & PFPeA & PFHxA & PFHpA & PFOA & PFNA & PFDA & PFUnDA & PFDoDA & PFTrDA & PFTeDA & PFBS & PFHxS & PFOS & PFDS & $\Sigma[$ PFAAs $]$ & $8: 2 \mathrm{FTCA}$ & FOSA & $\begin{array}{c}\text { di- } \\
\text { SAmPAP }\end{array}$ & $\begin{array}{c}\Sigma[\text { PFAA } \\
\text { precursors }]\end{array}$ & \\
\hline \multirow{17}{*}{$\begin{array}{c}\text { Before } \\
\text { oxidation }\end{array}$} & \multirow{13}{*}{ River water } & \multirow{9}{*}{$\begin{array}{l}\text { Main } \\
\text { river }\end{array}$} & 1 & $<0.31$ & 0.73 & 0.82 & 0.21 & 0.59 & 0.46 & $<0.01$ & 0.11 & $<0.09$ & $<0.01$ & 0.07 & 0.13 & $<0.14$ & 0.54 & 0.04 & 3.7 & $<0.32$ & 0.12 & $<0.01$ & 0.18 & 3.8 \\
\hline & & & 3 & $<0.31$ & 1.6 & 2.6 & 0.95 & 2.8 & 2.6 & 0.08 & 0.47 & $<0.09$ & $<0.01$ & $<0.03$ & 0.67 & 1.8 & 3.7 & $<0.02$ & 17 & $<0.32$ & 0.15 & $<0.01$ & 0.15 & 17 \\
\hline & & & 7 & 1.4 & 1.4 & 2.5 & 1.0 & 2.5 & 2.4 & 0.02 & 0.40 & $<0.09$ & 0.07 & $<0.03$ & 0.64 & 1.5 & 3.0 & $<0.02$ & 17 & $<0.32$ & 0.10 & $<0.01$ & 0.10 & 17 \\
\hline & & & 9 & $<0.31$ & 2.1 & 3.3 & 2.2 & 5.7 & 3.8 & 0.19 & 0.46 & $<0.09$ & $<0.01$ & 0.06 & 1.4 & 2.9 & 6.9 & 0.05 & 29 & $<0.32$ & 0.13 & $<0.01$ & 0.13 & 29 \\
\hline & & & 11 & 1.4 & 1.6 & 5.0 & 1.7 & 5.0 & 4.6 & 0.23 & 0.64 & $<0.09$ & 0.02 & $<0.03$ & 1.2 & 3.1 & 6.7 & 0.10 & 31 & $<0.32$ & 0.17 & $<0.01$ & 0.17 & 32 \\
\hline & & & 13 & $<0.31$ & 2.3 & 4.4 & 1.6 & 4.4 & 3.4 & 0.19 & 0.45 & $<0.09$ & $<0.01$ & 0.04 & 1.3 & 4.6 & 7.7 & $<0.02$ & 30 & $<0.32$ & 0.13 & $<0.01$ & 0.13 & 31 \\
\hline & & & 14 & $<0.31$ & 2.1 & 4.7 & 2.2 & 5.0 & 3.6 & 0.15 & 0.66 & $<0.09$ & 0.03 & 0.04 & 1.5 & 5.7 & 7.8 & $<0.02$ & 34 & $<0.32$ & 0.31 & $<0.01$ & 0.31 & 34 \\
\hline & & & 16 & $<0.31$ & 2.2 & 4.6 & 2.2 & 5.6 & 4.7 & 0.17 & 0.68 & $<0.09$ & 0.02 & $<0.03$ & 1.6 & 5.9 & 7.7 & $<0.02$ & 35 & $<0.32$ & 0.15 & $<0.01$ & 0.15 & 35 \\
\hline & & & 17 & $<0.31$ & 2.4 & 5.0 & 2.2 & 5.3 & 5.0 & 0.04 & 0.42 & $<0.09$ & 0.04 & $<0.03$ & 2.0 & 6.8 & 8.0 & 0.04 & 37 & $<0.32$ & 0.40 & $<0.01$ & 0.40 & 38 \\
\hline & & \multirow{3}{*}{$\begin{array}{c}\text { Branch } \\
\text { river }\end{array}$} & 19 & $<0.31$ & 0.47 & 0.25 & 0.20 & 0.88 & 0.26 & $<0.01$ & $<0.06$ & $<0.09$ & $<0.01$ & $<0.03$ & 0.66 & $<0.14$ & 1.4 & $<0.02$ & 4.1 & $<0.32$ & 0.21 & $<0.01$ & 0.21 & 4.4 \\
\hline & & & 21 & $<0.31$ & 1.2 & 1.4 & 1.8 & 3.7 & 1.4 & $<0.01$ & 0.16 & $<0.09$ & $<0.01$ & $<0.03$ & 0.95 & 0.94 & 3.6 & $<0.02$ & 15 & $<0.32$ & 0.27 & $<0.01$ & 0.27 & 15 \\
\hline & & & 22 & $<0.31$ & 1.5 & 1.5 & 1.8 & 3.4 & 1.5 & $<0.01$ & 0.09 & $<0.09$ & $<0.01$ & 0.18 & 1.3 & 1.0 & 4.0 & $<0.02$ & 16 & $<0.32$ & 0.61 & $<0.01$ & 0.61 & 17 \\
\hline & & Average & & 0.23 & 1.6 & 3.0 & 1.5 & 3.7 & 2.8 & 0.09 & 0.38 & 0.00 & 0.02 & 0.03 & 1.1 & 2.8 & 5.1 & 0.02 & 23 & 0.00 & 0.23 & 0.00 & 0.23 & 23 \\
\hline & \multirow{4}{*}{ STP effluent } & & 23 & $<0.31$ & 3.6 & 5.8 & 2.9 & 9.0 & 5.3 & 0.70 & 1.5 & $<0.09$ & $<0.01$ & $<0.03$ & 2.4 & 5.6 & 11 & $<0.02$ & 48 & $<0.32$ & 0.14 & $<0.01$ & 0.14 & 48 \\
\hline & & & 6 & 3.2 & 5.8 & 9.5 & 3.0 & 9.3 & 12 & 0.85 & 1.3 & $<0.09$ & 0.13 & $<0.03$ & 1.8 & 10 & 16 & $<0.02$ & 72 & $<0.32$ & 0.08 & $<0.01$ & 0.08 & 72 \\
\hline & & & 12 & 3.4 & 6.0 & 17 & 4.0 & 12 & 6.7 & 1.0 & 1.0 & $<0.09$ & 0.04 & $<0.03$ & 3.5 & 24 & 31 & $<0.02$ & 109 & $<0.32$ & 0.04 & $<0.01$ & 0.04 & 109 \\
\hline & & Average & & 2.2 & 5.1 & 11 & 3.3 & 10 & 8.0 & 0.85 & 1.3 & 0.00 & 0.05 & 0.00 & 2.6 & 13 & 19 & 0.00 & 76 & 0.00 & 0.09 & 0.00 & 0.09 & 76 \\
\hline
\end{tabular}


Table S3. Concentration of perfluoroalkyl acids and their precursors in river water and sewage treatment plant effluent samples before and after oxidation (ng $\left.\mathrm{L}^{-1}\right)$. (Continued)

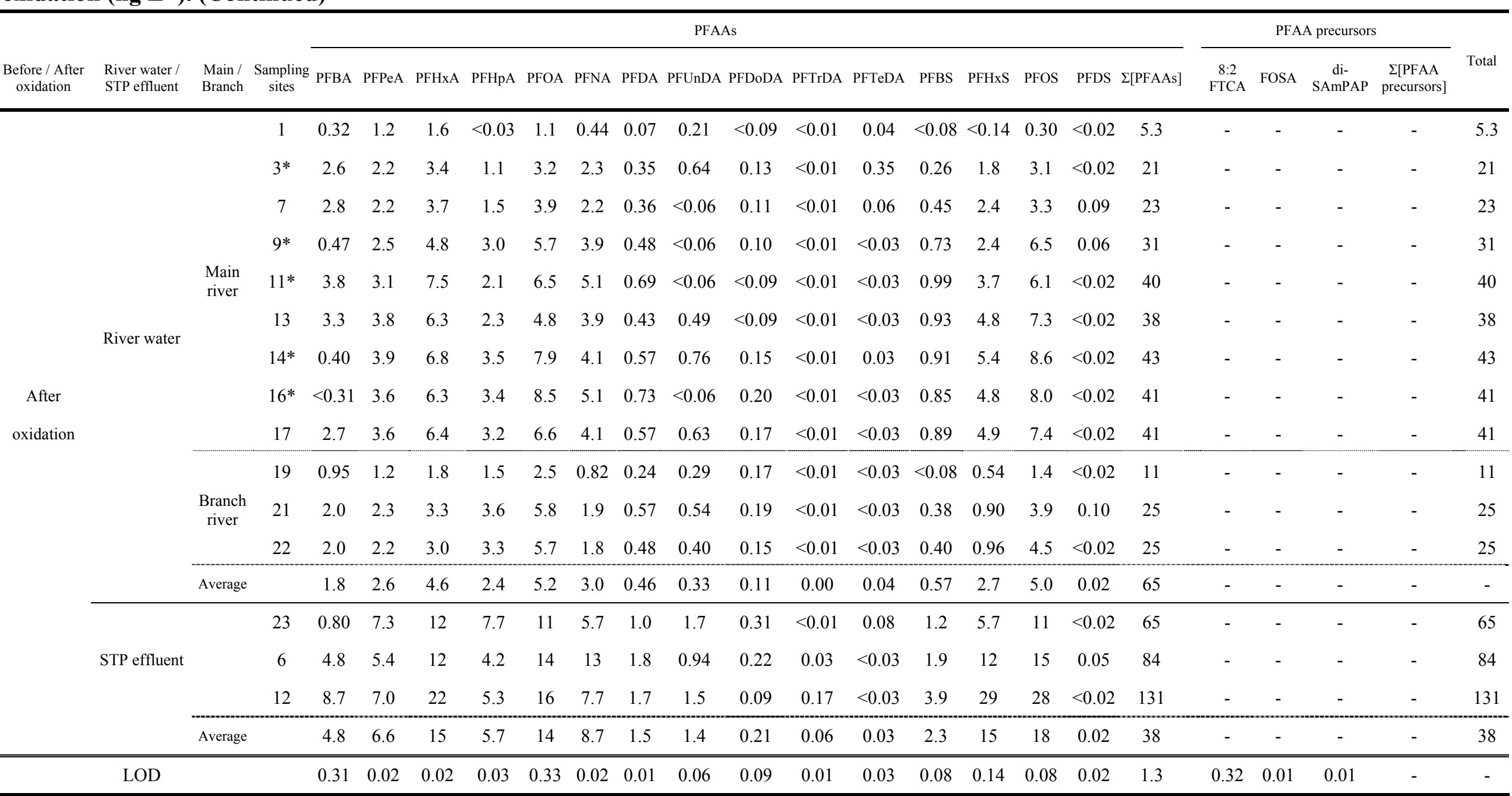

“-” indicates no data. 


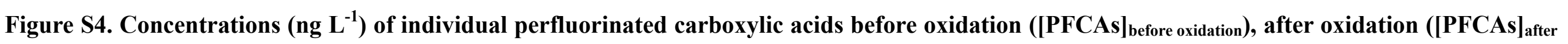
oxidation), their differences $(\triangle[\mathrm{PFCAs}])$ and their ratios $\left(\triangle[\mathrm{PFCA}] /[\mathrm{PFCA}]_{\text {before oxidation }}\right)$ in upstream, downstream and sewage treatment plant effluent samples.

\begin{tabular}{|c|c|c|c|c|c|c|c|c|c|c|c|c|}
\hline Area & Sites & & PFBA & PFPeA & PFHxA & PFHpA & PFOA & PFNA & PFDA & PFUnDA & PFDoDA & $\Sigma \Delta\left[\mathrm{PFCA}_{\mathrm{C} 4-\mathrm{C} 12}\right]$ \\
\hline \multirow{4}{*}{ Upstream } & \multirow{4}{*}{$1,3,7,19,21$ and 22} & {$[\mathrm{PFCA}]_{\text {before oxidation }}$} & 0.23 & 1.2 & 1.5 & 1.0 & 2.3 & 1.4 & 0.02 & 0.21 & 0.00 & 7.9 \\
\hline & & {$[\mathrm{PFCA}]_{\text {after oxidation }}$} & 1.8 & 1.9 & 2.8 & 1.8 & 3.7 & 1.6 & 0.34 & 0.35 & 0.12 & 14 \\
\hline & & $\Delta[\mathrm{PFCA}]$ & 1.5 & 0.70 & 1.3 & 0.84 & 1.4 & 0.16 & 0.33 & 0.14 & 0.12 & 6.5 \\
\hline & & Ratio of $\Delta[\mathrm{PFCA}] /[\mathrm{PFCA}]_{\text {before oxidation }}$ & 0.67 & 0.61 & 0.86 & 0.84 & 0.60 & 0.11 & - & - & - & - \\
\hline \multirow{4}{*}{ Downstream } & \multirow{4}{*}{$9,11,13,14,16$ and 17} & {$[\mathrm{PFCA}]_{\text {before oxidation }}$} & 0.23 & 2.1 & 4.5 & 2.0 & 5.2 & 4.2 & 0.16 & 0.55 & 0.00 & 19 \\
\hline & & {$[\mathrm{PFCA}]_{\text {after oxidation }}$} & 1.8 & 3.4 & 6.3 & 2.9 & 6.7 & 4.4 & 0.58 & 0.31 & 0.10 & 27 \\
\hline & & $\Delta[\mathrm{PFCA}]$ & 1.6 & 1.3 & 1.8 & 0.89 & 1.5 & 0.19 & 0.42 & -0.24 & 0.10 & 7.6 \\
\hline & & Ratio of $\Delta[\mathrm{PFCA}] /[\mathrm{PFCA}]_{\text {before oxidation }}$ & 0.67 & 0.62 & 0.40 & 0.44 & 0.29 & 0.40 & - & - & - & - \\
\hline \multirow{4}{*}{ STP effluent } & \multirow{4}{*}{6,12 and 23} & {$[\mathrm{PFCA}] \mathrm{b}_{\text {efore oxidation }}$} & 2.2 & 5.1 & 11 & 3.3 & 10 & 8.0 & 0.85 & 1.3 & 0.00 & 41 \\
\hline & & {$[\mathrm{PFCA}]_{\text {after oxidation }}$} & 4.8 & 6.6 & 15 & 5.7 & 14 & 8.7 & 1.5 & 1.4 & 0.21 & 58 \\
\hline & & $\Delta[\mathrm{PFCA}]$ & 2.6 & 1.4 & 4.5 & 2.4 & 3.7 & 0.70 & 0.64 & 0.10 & 0.21 & 16 \\
\hline & & Ratio of $\Delta[\mathrm{PFCA}] /[\mathrm{PFCA}]_{\text {before oxidation }}$ & 1.2 & 0.27 & 0.42 & 0.74 & 0.36 & 0.09 & 0.75 & 0.08 & - & - \\
\hline \multirow{4}{*}{ All sites } & \multirow{4}{*}{$\begin{array}{c}1,3,6,7,9,11,13,14,16 \\
17,19,21,22 \text { and } 23\end{array}$} & {$[\mathrm{PFCA}]_{\text {before oxidation }}$} & 0.62 & 2.3 & 4.5 & 1.9 & 5.0 & 3.8 & 0.24 & 0.56 & 0.00 & 19 \\
\hline & & {$[\mathrm{PFCA}]_{\text {after oxidation }}$} & 2.4 & 3.4 & 6.7 & 3.0 & 6.9 & 4.1 & 0.67 & 0.54 & 0.13 & 28 \\
\hline & & $\Delta[\mathrm{PFCA}]$ & 1.8 & 1.1 & 2.1 & 1.2 & 1.9 & 0.28 & 0.43 & -0.02 & 0.13 & 8.9 \\
\hline & & Ratio of $\Delta[\mathrm{PFCA}] /[\mathrm{PFCA}]_{\text {before oxidation }}$ & 2.8 & 0.46 & 0.47 & 0.63 & 0.38 & 0.07 & - & - & - & - \\
\hline
\end{tabular}

“-" indicates that the data could not be calculated because the denominator ([PFCA $]_{\text {before oxidation }}$ ) was 0 or $<$ LOD. 